\title{
Understanding the Rural-Rural Migration of Health Workers in Two Selected Districts of Tanzania
}

\author{
Nathanael Sirili $\mathbb{I D}^{1}$ and Daudi Simba ${ }^{2}$ \\ ${ }^{1}$ Department of Development Studies, Muhimbili University of Health and Allied Sciences, P.O. Box 65454, Dar es Salaam, Tanzania \\ ${ }^{2}$ Department of Community Health, Muhimbili University of Health and Allied Sciences, P.O. Box 65015, Dar es Salaam, Tanzania
}

Correspondence should be addressed to Nathanael Sirili; nsirili@yahoo.co.uk

Received 3 July 2019; Revised 2 November 2019; Accepted 4 December 2019; Published 22 January 2020

Academic Editor: Carol J. Burns

Copyright (c) 2020 Nathanael Sirili and Daudi Simba. This is an open access article distributed under the Creative Commons Attribution License, which permits unrestricted use, distribution, and reproduction in any medium, provided the original work is properly cited.

\begin{abstract}
Globally, rural-urban migration has been the focus in addressing the question of availability of health workers in rural areas. Often, the rural-rural migration of health workers, another important dimension is neglected. This study aimed to analyze the magnitude and the underlying factors for rural-rural migration of health workers in two rural districts of Tanzania. An exploratory comparative cross-sectional study adopting both quantitative and qualitative approaches was carried out in two districts of Kilwa in Lindi region, southern Tanzania, and Rombo in Kilimanjaro region, northern Tanzania. In a quantitative approach, 174 health workers (both clinicians and nonclinicians) filled in a self-administered questionnaire between August 2015 and September 2016. For the qualitative sub-study, 14 key informants that included health facilities in-charges and district health managers from the two districts were interviewed. In addition, three focus group discussions were conducted with members of the health facilities committee, in the two districts. Over $40 \%$ of health workers migrated from one workstation to another between 2011 and 2015 . Close to $70 \%$ of the migrated health workers, migrated within the same districts. The proportion of health workers migrated was higher in Kilwa compared to Rombo. However, the difference was not statistically significant. The major underlying factors for migration in both districts were: Caring for the family and Unfavorable working and living conditions. In Kilwa, unlike Rombo, rejection by the community, superstitious beliefs, and lack of social services, were the other major factors underlying migration of the health workers. While addressing rural-urban migration, attention should be paid also to the rural-rural migration of health workers. Lastly, addressing the migration of health workers is a multi-dimensional issue that needs the engagement of all stakeholders within and beyond the health sector.
\end{abstract}

\section{Background}

Globally, the retention of the skilled health workforce in rural areas remains to be among the major challenges facing many health systems $[1,2]$. While the global population is equally divided between rural and urban areas [3], the available health workforce is not equally divided. Estimates show that only $38 \%$ of nurses and $24 \%$ of the physicians serve the rural population [4]. The major cause of the inequitable distribution has been stated to be the rural-urban migration [5-7] attributed to; poor working condition in the rural areas, poor social services, poor supervision from immediate supervisors, poor living conditions, limited opportunities for career growth and limited alternative sources of income [8-12].

Sub-Saharan Africa (SSA), home to $11 \%$ of the global population and a host to $25 \%$ of the global burden of diseases has only $3 \%$ of the global health workforce. The latter leaves SSA with a deficit of more than one million new health workers [13]. As for other parts of the world, SSA suffers from the ruralurban divide in the little available health workforce. With close to $60 \%$ of the population living in rural areas less than $50 \%$ of the health workforce are in rural areas [14]. The causes for the depicted situation are not unique to those for the global level although the magnitude varies from one country to another.

Tanzania, a country within SSA, suffering a shortage of over $50 \%$ of the required health workforce has only $31 \%$ of health workers serving the rural population that accounts for about $75 \%$ of the total population $[15,16]$. The situation is worse for physicians, where only $26 \%$ were in rural areas by 2014 [17]. It is documented that, challenging work environment, lack of uniform career pathways, nonuniform financial incentives across districts, lack of social amenities and poor 
living conditions are among the push factors for health workers to leave the rural districts [18-21].

The shortage of health workforce in rural areas is observed despite the efforts undertaken by the government of Tanzania in the provision of both financial and nonfinancial incentives [19]. The nonfinancial incentive strategies have included; opportunities for further education, proactive staff recruitment, bonding schemes, contracting arrangements, and provision of accommodation to the health workers $[8,19$, 21-23]. While the financial incentive strategies have faced budgetary difficulties most of the nonfinancial incentives have had budgetary implications thus rendering its implementation difficult [24]. While these strategies aim at reducing the rural-urban migration, another form of migration, rural-rural migration, has not been brought into the scene. Anecdotal information suggests that within rural districts there exists migration of health workers from one facility to another. The latter leaves some of the facilities in a worse situation. However, the magnitude and the factors contributing to the rural-rural migration of health workers in Tanzania are not documented.

This study therefore aimed (i) to document the magnitude of migration of health workers within the rural districts and (ii) to explore the factors underlying the migration of health workers in rural districts of Tanzania.

\section{Methods}

2.1. Study Design. An exploratory comparative cross-sectional study, utilizing both qualitative and quantitative approaches was conducted in Kilwa and Rombo districts in two regions of Tanzania between August 2015 and September 2016.

2.2. Study Setting. Tanzania operates a decentralized health care system, where the health care system is organized into a pyramid structure of three levels. (i) The primary level, which contains the district hospital and health facilities below it, which are health centres, dispensaries and health posts, (ii) the secondary level, which comprises the regional and regional referral hospitals and the tertiary level, which includes zonal referral, specialized consultant hospitals, and (iii) the national hospitals. In terms of staffing, the primary level is staffed by health workers with certificate, diploma, and bachelor level of education; the secondary level is staffed by health workers of whom majority have bachelor level of education with few of up to masters level of education, while the tertiary level is staffed by health workers of whom majority are bachelor and masters holders with few who have a level of education above masters level [25]. The ministry responsible for health oversees the overall health services provision in all three levels [26].

The country is subdivided into 7 geo-political zones (Table 1), 25 regions and 185 districts. Kilwa is one of the six districts comprising Lindi region that is found in the southern zone of Tanzania. This is one of the zones that have severe health workforce shortage [23].

Rombo district is one of the six districts forming the Kilimanjaro region in the northern zone which is one of the
TABLE 1: Geo-political zones in Tanzania.

\begin{tabular}{|c|c|}
\hline Zone & Regions \\
\hline Central zone & Dodoma and Singida \\
\hline Eastern zone & Coast, Dar es Salaam, and Morogoro \\
\hline Lake zone & $\begin{array}{c}\text { Kagera, Mara, Mwanza, Shinyanga, } \\
\text { Simiyu, and Geita }\end{array}$ \\
\hline Northern zone & $\begin{array}{c}\text { Arusha, Kilimanjaro, Manyara, and } \\
\text { Tanga }\end{array}$ \\
\hline Southern zone & Lindi and Mtwara \\
\hline Southern highlands & Iringa, Mbeya, Ruvuma, and Njombe \\
\hline Western zone & Katavi, Kigoma, Rukwa, and Tabora \\
\hline
\end{tabular}

zones with relatively better-health workforce density in the country [23]. Both Kilwa and Rombo are considered as rural districts.

2.3. Study Population. This study had two study populations, for the quantitative data, all health workers from the selected health facilities in the two districts who were available during the data collection period were involved. For qualitative data collection; District Medical Officers, District Health Secretaries, the District hospital Medical Officers in charges, Health Centres medical in-charges, dispensaries medical incharges and members of the health facility committees in the selected health facilities were involved.

\subsection{Sample Size}

2.4.1. Quantitative Sub-Study. All health workers available during the data collection period in the selected facilities were involved.

2.4.2. Qualitative Sub-Study. Fourteen key informant (KI) interviews and three focus group discussions were conducted. Data collection was stopped after attaining information saturation.

\subsection{Sampling Strategy}

2.5.1. Quantitative Sub-Study. A multi-stage sampling was adopted to obtain the health workers participated in this study (Figure 1).

2.5.2. Qualitative Sub-Study. Purposive sampling was used to identify the key informants (KI) and focus group discussion (FGD) participants by virtue of their positions and responsibilities concerning health workers' management at the district and facility level. In this regard, KI included all health facility in-charges, District Medical Officers, District Health Secretaries and one Human resources Officer from the two districts while the FGD members included health facility governing committee members from the health facilities included.

\subsection{Data Collection}

2.6.1. Quantitative Data Collection. Swahili self-administered questionnaire was used, the questionnaire contained both 
Stage 1: Selection of zones
(purposive sampling)

Stage 2: Selection of regions

(purposive sampling)

Stage 3: Selection of districts

(random sampling)

Stage 4: Selection of wards (random sampling)

Stage 5: Selection of villages and health facilities

(all villages with health facilities)

$* * *$ HC-health centre
$* * *$ disp-dispensary

Stage 6: Selection of health workers

(all available and who consented)

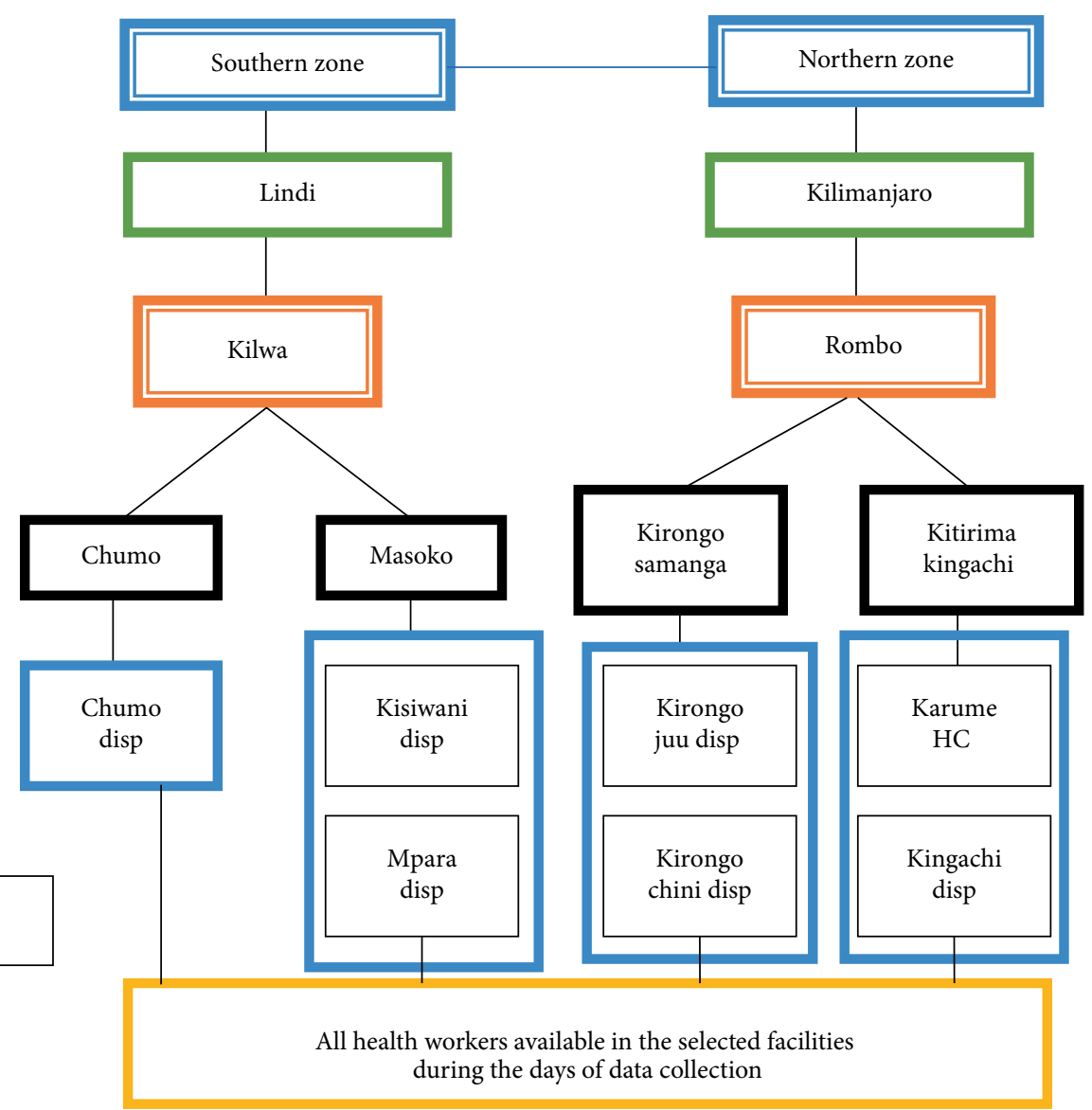

FIGURE 1: Multi-stage sampling. open and closed-ended questions. The questions sought information on; duration at workplace, place of origin (domicile), previous workstation within the past five years, reasons for migrating to the current workstation, work environment, incentives, challenges faced at previous, and current workstation and how were they overcome and lastly the reasons for staying in current workstation. The research assistant supplied the self-administered questionnaires to the HWs.

2.6.2. Qualitative Data Collection. Using a Swahili semistructured interview guide and focus group discussion guide, we conducted a total of 14 key informant interviews and three focus group discussions comprised of 19 participants (Table 2). Work experience of the key informants varied from 3 years to 12 years, with an age range between 29 years and 46 years with a minimum of a diploma level of education up to a master's degree. For the FGDs age range was between 35 years and 54 years and a minimum level of primary school education. All KI-interviews and FGDs were audio-recorded using a digital voice recorder. The audio recorder was kept secured by the researcher. The interviews took between 30 minutes and 60 minutes while the FGDs lasted between 60 minutes and 90 minutes. The interviews were carried out in the offices or designated room by the informants. The FGDs were carried out at the offices of the village government or
TABLE 2: Participants for KIIs and FGDs.

\begin{tabular}{lccc}
\hline Category & Male & Female & Total \\
\hline Key informants & & & \\
District Medical Officers & 2 & 0 & 2 \\
District Health Secretaries & 0 & 2 & 2 \\
Health facility-Incharges & 4 & 5 & 9 \\
Human resources Officer & 0 & 1 & 1 \\
Focus group discussion participants & 11 & 8 & 19 \\
\hline
\end{tabular}

a classroom in a nearby school as identified and arranged by the village leader. The researcher was accompanied by a research assistant who took notes during the interviews and FGDs.

\subsection{Data Entry and Analysis}

2.7.1. Quantitative Data Analysis. All the questionnaires were coded and entered in a computer and analysis was aided by SPSS software version 21. For the open-ended questions, reading, re-reading, and then post-coding was done. Descriptive analysis was done and data presentation was done through frequency distribution tables and figures. Cross-tabulation was used for comparing variables for the two districts, a $p$-value of 0.05 was considered statistically significant. 
TABLE 3: Socio-demographic characteristics of health workers responded to the questionnaire.

\begin{tabular}{|c|c|c|c|c|c|c|}
\hline \multirow[t]{2}{*}{ Characteristic } & \multicolumn{2}{|c|}{$\begin{array}{c}\text { Kilwa } \\
N=110\end{array}$} & \multicolumn{2}{|c|}{$\begin{array}{l}\text { Rombo } \\
N=64\end{array}$} & \multicolumn{2}{|c|}{$\begin{array}{c}\text { Total } \\
N=174\end{array}$} \\
\hline & Frequency & $\%$ & Frequency & $\%$ & Frequency & $\%$ \\
\hline \multicolumn{7}{|l|}{ Age } \\
\hline Up to 25 & 13 & 11.8 & 8 & 12.5 & 21 & 12.1 \\
\hline $26-35$ & 37 & 33.6 & 16 & 25.0 & 53 & 30.5 \\
\hline $36-45$ & 24 & 21.8 & 11 & 17.2 & 35 & 20.1 \\
\hline $46-55$ & 23 & 20.9 & 8 & 12.5 & 31 & 17.8 \\
\hline $56-65$ & 3 & 2.7 & 4 & 6.3 & 7 & 4.0 \\
\hline Not displayed & 10 & 9.1 & 17 & 26.6 & 27 & 15.5 \\
\hline \multicolumn{7}{|l|}{ Sex } \\
\hline Male & 35 & 31.8 & 11 & 17.2 & 46 & 26.4 \\
\hline Female & 64 & 58.2 & 38 & 59.4 & 102 & 58.6 \\
\hline Not displayed & 11 & 10.0 & 15 & 23.4 & 26 & 14.9 \\
\hline \multicolumn{7}{|l|}{ Marital status } \\
\hline Married & 72 & 65.5 & 32 & 50.0 & 104 & 59.8 \\
\hline Not married & 33 & 30.0 & 25 & 39.1 & 58 & 33.3 \\
\hline Status not displayed & 5 & 4.5 & 7 & 10.9 & 12 & 6.9 \\
\hline \multicolumn{7}{|l|}{ Employer } \\
\hline Ministry of health & 2 & 1.8 & 9 & 14.1 & 11 & 6.3 \\
\hline $\begin{array}{l}\text { District executive } \\
\text { director }\end{array}$ & 108 & 98.2 & 48 & 75.0 & 156 & 89.7 \\
\hline Other & 0 & 0.0 & 7 & 10.9 & 7 & 4.0 \\
\hline \multicolumn{7}{|l|}{ Cadre } \\
\hline Clinicians & 11 & 9.9 & 10 & 15.6 & 21 & 12 \\
\hline Nurses & 45 & 40.9 & 25 & 39.1 & 70 & 40.2 \\
\hline Other & 37 & 33.7 & 9 & 14.2 & 46 & 26.5 \\
\hline Not specified & 17 & 15.5 & 20 & 31.3 & 37 & 21.3 \\
\hline
\end{tabular}

Key: Clinicians $=$ Assistant Medical Officers + Clinical Officer + Doctor of Dental Surgery + Medical Assistants + Medical Officers. Nurses $=$ Nurses + Assistant Nursing Officers + Midwives. Other $=$ Assistant Record officer + Assistant Health Officers + Data Clerk + Health Attendants + Health Officers + Laboratory Technicians + Medical Attendants.

2.7.2. Qualitative Data Analysis. Interviews and FGDs were first transcribed verbatim. Qualitative conventional content analysis was used for data analysis. This involved reading and re-reading the interview transcripts to get familiarization with the data. A preliminary codebook was prepared based on study objectives and familiarity with the data. The codebook was translated from Kiswahili to the English language. The codebook was pre-tested by the two authors independently by coding two similar transcripts, where the coding was almost similar and no further changes to the codebook were made at this stage. The codebook was then copied in NVIVO version 11 software before coding. Condensed meaning units were identified from the interviews and coding was done with the aid of the NVIVO software. The coding process was iterative and new codes were identified that either supplemented the prior codes or added as new codes. Then, similar codes were grouped together and these were abstracted into subcategories. Basing on similarities and differences between the sub-categories, they were further grouped into categories to reflect both the latent and manifest content. The final codes, sub-categories, and categories were discussed and agreed by both authors. In this analysis, the District Medical Officers and District Health Secretaries are referred to as Health Managers.
2.8. Ethical Considerations. Ethical clearance for this study was obtained from the Senate Research and Publications Committee of the Muhimbili University of Health and Allied Sciences in Tanzania. Permission for data collection was obtained from the Ministry responsible for health, Ministry responsible for regional administration and local government authorities, regional and district authorities; and in-charges of health facilities. Written informed consent was obtained from each study participant prior to the interview, focus group discussion or filling in a questionnaire.

\section{Results}

The results are organized into two sections, the first part presents the socio-demographic characteristics of the health workers who answered the self-administered questionnaires and the magnitude of the rural-rural migration. While the second part presents the findings on factors underlying ruralrural migrations.

\subsection{Socio-Demographic Characteristics of Health Workers} Responded to the Self-Administered Questionnaire. In this study, 174 health workers responded to a self-administered 
TABLE 4: Migration of health workers between 2011 and 2015 in Kilwa and Rombo districts.

\begin{tabular}{lccccccc}
\hline \multirow{2}{*}{$\begin{array}{l}\text { Cadres } \\
N=73\end{array}$} & $\begin{array}{c}\text { Within district } \\
n(\%)\end{array}$ & $\begin{array}{c}\text { From other } \\
\text { districts } n(\%)\end{array}$ & $\begin{array}{c}\text { Within district } \\
n(\%)\end{array}$ & $\begin{array}{c}\text { From other } \\
\text { districts } n(\%)\end{array}$ & $\begin{array}{c}\text { Within district } \\
n(\%)\end{array}$ & $\begin{array}{c}\text { From other } \\
\text { districts } n(\%)\end{array}$ & $\begin{array}{c}\text { Total } \\
\text { migrated } n \\
(\%)\end{array}$ \\
\hline Clinicians & $0(0)$ & $3(100)$ & $2(50)$ & $2(50)$ & $2(28.6)$ & $5(71.4)$ & $7(9.6)$ \\
Nurses & $17(80.9)$ & $4(19.1)$ & $5(45.5)$ & $6(54.5)$ & $22(68.9)$ & $10(31.1)$ & $32(43.8)$ \\
Other & $16(88.9)$ & $2(11.1)$ & $2(50)$ & $2(50)$ & $18(81.8)$ & $4(18.2)$ & $22(30.1)$ \\
Not specified & $5(55.6)$ & $4(44.4)$ & $3(100)$ & $0(0)$ & $8(66.7)$ & $4(33.3)$ & $12(26.5)$ \\
\hline Total & $38(74.5)$ & $13(25.5)$ & $12(54.5)$ & $10(45.5)$ & $50(68.5)$ & $23(31.5)$ & $73(100)$ \\
\hline
\end{tabular}

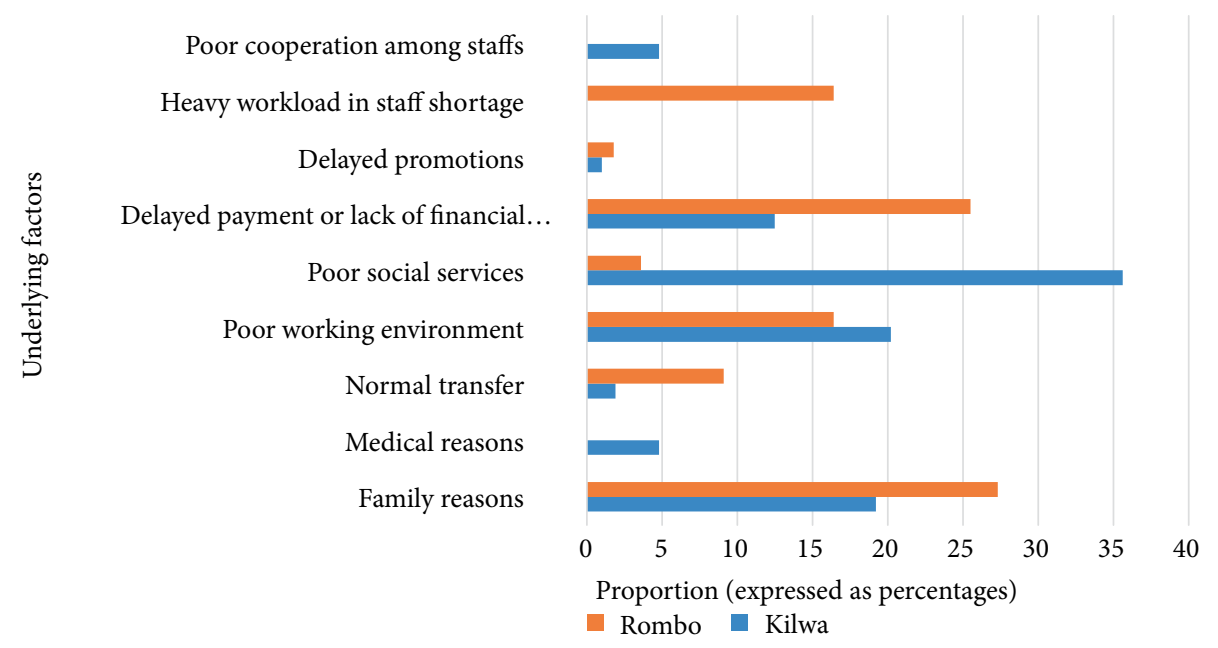

FIGURE 2: Underlying factors for migration.

questionnaire. Over $60 \%$ of the respondents were from Kilwa. Among the participants, 58.6\% were female and $26.4 \%$ were male and $14.9 \%$ did not indicate their sex. Sixty-percent of all respondents were married. About $90 \%$ of the health workers participated in this study were employed by the District Executive Directors (Table 3).

\subsubsection{Magnitude of the Rural-Rural Migration of Health} Workers between 2011 and 2015. Forty-two percent of all health workers who filled in the self-administered questionnaire (73/174), migrated from one workstation to another between 2011 and 2015 (Table 4). About sixty-nine percent of the migrated health workers moved within the same districts while $31 \%$ joined the two districts from other districts. Most of the health workers who migrated, $97.3 \%$ indicated their marital status and out of these, $71.8 \%$ were married. Migration within the districts was higher among the married, $72.5 \%$ compared to $55 \%$ of those who were single. The difference in proportions of migration among the married and those who were single was statistically significant $(p=0.04)$.

Between the two districts, the proportion of health workers who migrated was higher in Kilwa, $46.4 \%$ compared to $34.4 \%$ in Rombo. However, this difference was not statistically significant $(p=0.09)$. The proportion of health workers involved in this study who joined the two districts (in-migration) from 2011 to 2015 was slightly higher in Rombo, 15.6\% compared to $11.8 \%$ in Kilwa. However, the difference was not statistically significant $(p=0.08)$.
3.1.2. Factors Underlying Migration of Health Workers within Districts. Majority of the study participants (65.4\%) mentioned unsupportive working conditions attributed to the poor working environment, heavy workload, underequipped facilities and poor social services; and family reasons attributed to following a spouse and going close to a family as the major reasons for migration in the two districts. The underlying factors for migration varied across the two districts. Poor social services were more pronounced in Kilwa district while family reasons were the major underlying factors for migration in Rombo district (Figure 2). In both districts, normal transfers (those initiated by the employer) were less than $10 \%$ among those who migrated with $2 \%$ in Kilwa and $8 \%$ in Rombo.

Similarly to what was depicted in the quantitative findings (Figure 1), caring for the family and poor work and living environment came out strongly from qualitative findings as important sub-categories constituting the factors underlying the migration of health workers in the two districts.

3.2. Caring for the Family. Majority of the informants attributed the migration of health workers from one working station to another to the need to care for their families. Caring for the family was expressed in terms of; living with their spouse, children and parents or staying at a close distance where the health workers have access to their families.

Informants further added that for the female health workers, the need to migrate to follow the husband was higher 
than for men. The desire to be close to a spouse was very strong to the extent that some workers were ready to resign from their jobs as one of the informants said.

\section{"...Since I came here more than ten years ago, two health workers have been brought and left; one midwife and a clinical officer. The midwife was struggling to leave for over a year but when we sat and talked to her she understood and continued to work.... but after she got married she was ready to resign her job to fol- low her husband, she was therefore allowed to leave..." (Health facilityin-charge-Kilwa)}

3.3. Poor Work and Living Environment. Informants stated poor work environment linked to superstitious practices by the indigenous community, heavy workload in ill-staffed facilities, cultural differences between indigenous and health workers, availability of socio-economic services and rejection by the community.

3.3.1. Superstitious Practices. In Kilwa District, informants reported to be affected by superstitious practices by the indigenous; and most affected were the very remote areas. This has contributed to the migration of health workers from remote to semi-urban areas and sometimes to other districts when the opportunity to migrate within the district was denied. Superstitious practices were reported to make it difficult for some health workers to live with the indigenous in the same compound as tenants.

\section{"...this community practices superstition a lot...now it happens a worker come and tell you, I have failed I can't stay here with these witches give me a transfer or I resign...now as you know the situation you give her/him the recommendation letter for transfer..." (Health manager-Kilwa)}

3.3.2. Heavy Workload due to Ill-Staffed Facilities. Informants stated that some facilities were overwhelmed with heavy workload du. Since some of the cadres are either not available or few, those available have to shoulder multiple tasks. This has led to the migration of some health workers to better-staffed facilities and thus worsening the situation in the facility they left.

\footnotetext{
"...We are supposed to be nine in this facility but we are only four... there is no clinician or a laboratory staff here, there are two midwives, one is the in-charge and the rest are health attendants... we see patients, we carry out laboratory tests and we prescribe... this is not our role both in procedure and training..." (Health facility in-charge-Kilwa).
}

Health managers in Rombo reported having half of the required staff need. But whenever they make a request for additional health workers, they received a large number of low cadres that they did not request, the majority of them being medical attendants.

\footnotetext{
"... Every time we request for health workers we receive less than what we requested ... sometimes we are given cadres we did not request, to the extent that we now have a large number of medical attendants that exceed our staffing norm..." (Health manager-Rombo)
}

3.3.3. Tennant-Landlord Cultural Differences. Lack of housing for health workers in many areas in the two districts forces the health workers to rent houses and sometimes live in the same houses with the indigenous community. Informants stated in Kilwa cultural differences was a major challenge. In Rombo there were not enough houses for health workers as for Kilwa, securing accommodation and staying with the indigenous was not a problem as reported in Kilwa. The latter, was the reason for most health workers in Kilwa district to migrate and even resign, if not allowed to shift to another facility.

"...At least we have two houses now, they have helped us if compared to the time when we arrived here. We had to live with landlords in their homes. It was very difficult to stay with them due to differences in culture... however, currently we are only two instead of nine (a blessing in disguise) ... if more health workers will be brought the housing problem will recur..." (Health facility in-charge-Kilwa)

3.3.4. Socio-Economic Services. Many informants mentioned the variation in the availability of social services and economic opportunities in different places to drive the health workers' migration. In Kilwa District, banking services were only found at Kilwa town. Other places were lacking even Automated Teller Machines (ATMs). This forced a health worker to go to Kilwa town every month to collect the salary. In some places of Kilwa, even mobile telephone communication was nonexistent.

"...the banking services are all concentrated here at the district town centre, so all health workers have to travel each month to access banking services.... some health workers start a journey on $23^{\text {rd }}$ day of the month with the expectation of getting their salaries on the $25^{\text {th }}$..." (Health manager-Kilwa)

In Rombo, two main issues were the major challenges; shortage of safe and clean water in some places and limited opportunity for land ownership. In some places, workers were ready to stay far from their working place to have access to clean and safe water.

“... Apart from the water challenge, everyone here values his/her land...that makes it hard to sell even a small piece of land to a foreigner. ...Failure to own land undermines efforts to retain our workers since no one would tolerate being a tenant throughout his/her lifetime ..." (Health manager-Rombo)

3.3.5. Rejection of Health Workers by the Community. Rejection of some health workers by the community through their political leaders was another reason reported to influence the migration of health workers. In some places, community leaders went far to decide who should be posted to their village.
"...these political leaders come to you and tell you we don't need this health worker...for instance, there were two health workers in one facility, an old woman and a young lady, the political leader came to my office and said that they (community) didn't want the young lady... a few days later the lady came and said the leaders didn't want her and they are embarrassing her. So she decided to leave..." (Health manager-Kilwa)

Contrary to the reported situation in Kilwa, in Rombo district informants reported that community leaders valued health workers in their places. To them, if a health worker left the health facility it was putting their community at high health risks. 
"...the health workers are there for us, and we value them. For instance, this Saturday we (the community) will be cleaning the surroundings of the health Centre... they take care of our health, we must take care of them so that we make them stay with us..." (FGD member Rombo).

\section{Discussion}

We aimed to analyze the magnitude of health workers' migration and the underlying factors for rural-rural migration by conducting our study in two rural districts of Rombo in the northern zone and Kilwa in the southern zone of Tanzania. Nearly half of the health workers who participated in this study migrated from one workstation to another in a period of five years. Family, living and work-environment factors were stated as the major factors underlying migration of the health workers in the two districts.

Based on the socio-economic and cultural variations between the two districts, although not precisely representative, we feel that our findings reflect the situation of health workers' migration in many rural districts of Tanzania. The findings from this study like for other previous studies in Tanzania and other places $[6,8,9,13,15,27]$, underscores the fact that retention of health workers especially in rural areas is a complex phenomenon and multiple dimensions must be considered in addressing this challenge.

As revealed by the findings of our study the health workers' migration has another dimension that is often given less attention, the rural-rural migration. Many studies have a focus on assessing the magnitude and causes of the rural-urban migration of health workers in many parts of the world including Tanzania [9, 19, 27-29]. Migration of $42.5 \%$ among 174 health workers who participated in this study in a period of five years in only eight facilities rings an alarm on the magnitude of migration of health workers in rural districts. Even though the majority $(61 \%)$ of these health workers migrated within the same districts, the sending facilities are grossly affected and this has a bearing on the health services provision. The shortage of skilled health workers is more pronounced in rural areas of Tanzania compared to the urban ones [30]. This situation was similarly reported in Nigeria where around half of the health workers were serving the rural population by 2010 despite the skewness of the population distribution [31]. Therefore, any skewness in the distribution of the available health workers in rural areas causes serious deleterious effects on health services provision. In Tanzania, it may partly be argued that the poor maternal health indicators in rural areas compared to the urban areas [32] reflect some of these effects.

Consideration of the family as a factor underlying emigration as revealed in our findings is not unique to these two districts. In another study carried in Tanzania by Sirili et al. [21], being close to the family or relatives affects both intention to choose workplace destination and retention after reporting. This is also similar to what was found by Utah in South Africa [9]. In our study, 22\% of the responses on reasons for migration were on family reasons and ranked second after poor social services that were reported by $24 \%$ of the respondents. In our study, over $70 \%$ of those who migrated from one station to another were married. The latter, therefore, sends a message to the health workforce planners at the district and the national levels to consider the workstation of the partner during placement of a health worker who is already married or is about to be married in order to minimize the chance for migration.

Our study further revealed that the community has an important role to play in the migration of health workers. As revealed in this study in some places health workers were rejected by the community members due to different reasons including socio-cultural practices. The community may directly reject the health workers as seen in some places or by providing unsupportive living conditions that may push the health workers to emigrate [15]. Socio-cultural factors like superstitious beliefs as revealed in this study comprise another dimension on how the community can provide an unsupportive living environment and thus underlying the migration of health workers in rural Tanzania. Although, constitutionally, Tanzania does not recognize the existence of superstitious practices, the existence of cultural diversity within the country, within regions and districts needs to be considered during the health workforce planning. To start with, we recommend that the local government authorities in each place device educational strategies to educate the community at large on how their cultural practices negatively affect the retention of the health workers and in turn affecting their own health. In the long run, the training system should try to accommodate many students with rural backgrounds as well as increasing rural attachment during the training [28]. WHO emphasizes the role of community as an important attribute for the retention of health workers; the respect bestowed by the community to health workers brings into them a sense of satisfaction and thus reduces the likelihood of emigration [4].

Unfavorable working conditions and lack of or poor social services were other major underlying factors for the migration of health workers in rural areas revealed by our study. These findings are similar to what was found by other studies carried out in Tanzania $[8,15,20,29,33,34]$. As for the previous studies, lack of access to Banking services, good schools for the education of their children, good transport and reliable communication systems pushes the health workers to emigrate from rural remote areas to other places where the services are accessible. This, therefore, adds to the fact that addressing the retention of health workers in rural areas is a complex phenomenon that calls for concerted efforts from all partners in both the public and private sectors. This stance is similar to what was expressed by the joint initiatives in higher learning meeting in 2004 and later echoed by WHO in 2009, that retention of health workers is a shared responsibility $[4,35]$.

4.1. Study Limitations. This study was conducted in only two selected districts in the country. This may limit the generalizability of the results reported in this study. However, the complementarity of the quantitative and qualitative approaches in data collection and analysis adds to the depth of information obtained and the methodology rigor thus mitigating this limitation. The inclusion of health workers of various cadres at a health facility and district levels enriched 
the quality of our data to answer the intended research question. The involvement of health managers ensured that information obtained is inclusive of both the management and the day-to-day providers of health services in the district.

Again, the fact that the researchers are health workers working at the public health University, this may have introduced social desirability from the study participants. However, triangulation of sites, methods of data collection and respondents is believed to have offset the social desirability.

\section{Conclusion}

The findings of this study underscore that the migration of health workers in Tanzania does not only manifest as rural-urban migration but also rural-rural migration within the rural districts. Although there is a higher proportion of health workers migrating in Kilwa than Rombo, both of them are unacceptably high. While many migration-underlying factors are similar, superstitious practices and health workers' rejection by the community are unique for Kilwa. Policymakers and planners should consider the cultural diversities, family reasons like marital status and occupation of the partner in the placement of health workers. Multi-stakeholders' engagement is needed in addressing the wider question of socio-economic services in rural areas for the successful retention of health workers.

\section{Data Availability}

Data set and qualitative transcripts for this study are available, however sharing is limited for confidentiality reasons, specifically for the qualitative transcripts.

\section{Conflicts of Interest}

The authors declare that there is no conflicts of interest regarding the publication of this paper.

\section{Acknowledgments}

The authors sincerely acknowledge the support from Sida that funded this study through Muhimbili University of Health Sciences under the small grants projects. We also acknowledge the support from the Ministry of Health, Community Development, Gender, Elderly, and Children and the local government authorities and all research participants. This study was funded by Muhimbili University of Health Sciences through its Swedish International Development Cooperation Agency-Sida support under bilateral agreement 2009-2014 as small grant support for faculty development.

\section{References}

[1] Liese, B. and G. Dussault, "The state of the health workforce in sub-saharan Africa: evidence of crisis and analysis of contributing factors," Washington, DC: World Bank, 2004.
[2] World Health Organization, "The world heath report 2006 : working together for health Geneva," WHO, Switzerland, 2006.

[3] UN, "World urbanization prospects: the 2014 revisionhighlights," UN, 2014.

[4] C. Dolea, L. Stormont, D. Shaw, P. Zurn, and J. M. Braichet, "Increasing access to health workers in remote and rural areas through improved retention. In First expert meeting to develop evidencebased recommendations to increase access to health workers in remote and rural areas through improved retention," World Health Organization, Geneva, 2009.

[5] M. Munga and D. Mbilinyi, "Non-financial incentives and retention of health workers in Tanzania," National Institute for Medical Research, Dar es Salaam, 2008.

[6] G. Dussault and M. C. Franceschini, "Not enough there, too many here: understanding geographical imbalances in the distribution of the health workforce," Human Resources for Health, vol. 4, no. 1, p. 12, 2006.

[7] J. Nyoni, A. Gbary, M. Awases, P. Ndecki, and R. Chatora, "Policies and plans for human resources for health. Guidelines for countries in the WHO African region," WHO Regional Office for Africa, Brazzaville, 2006.

[8] F. Manzi, J. A. Schellenberg, G. Hutton et al., "Human resources for health care delivery in Tanzania: a multifaceted problem," Human Resources for Health, vol. 10, no. 1, p. 3, 2012.

[9] U. Lehmann, M. Dieleman, and T. Martineau, "Staffing remote rural areas in middle-and low-income countries: a literature review of attraction and retention," BMC Health Services Research, vol. 8, no. 1, p. 19, 2008.

[10] E. Nketiah-Amponsah, C. Fenenga, S. Duku, N. de Spieker, T. F. Wit, and F. Meslé, "Rural-urban differences in health worker motivation and quality care in selected health facilities in Ghana,"

[11] E. K. Darkwa, M. S. Newman, M. Kawkab, and M. E. Chowdhury, "A qualitative study of factors influencing retention of doctors and nurses at rural healthcare facilities in Bangladesh," BMC Health Services Research, vol. 15, no. 1, p. 344, 2015.

[12] L. C. Chen, "Striking the right balance: health workforce retention in remote and rural areas," Bulletin of the World Health Organization, vol. 88, no. 5, p. 323-A, 2010.

[13] S. C. Anyangwe and C. Mtonga, "Inequities in the global health workforce: the greatest impediment to health in sub-Saharan Africa," International Journal of Environmental Research and Public Health, vol. 4, no. 2, pp. 93-100, 2007.

[14] U. Desa, "World economic and social survey 2004: International Migration," United Nations Department of Economic and Social Affairs (UN DESA), NY, UN, 2004.

[15] A. Shemdoe, G. Mbaruku, A. Dillip et al., "Explaining retention of healthcare workers in Tanzania: moving on, coming to "look, see and go", or stay?" Human Resources for Health, vol. 14, no. 1, p. 2, 2016.

[16] URT, "National Bureau of Statistics. National population and housing census 2012," United Republic of Tanzania, 2013.

[17] URT, "Ministry of health and social welfare. Human resource for health country profile 2013/2014," United Republic of Tanzania, Dar es Salaam, 2014.

[18] O. Mæstad, "Human resources for health in Tanzania: challenges, policy options and knowledge gaps," vol. 2006, Tech. Rep. 3, 2006, CMI report.

[19] URT, "Ministry of health and social welfare. Human resources for health strategic plan 2008-2013," United Republic of Tanzania, 2007. 
[20] M. A. Munga and O. Mæstad, "Measuring inequalities in the distribution of health workers: the case of Tanzania," Human Resources for Health, vol. 7, no. 1, p. 4, 2009.

[21] N. Sirili, G. Frumence, A. Kiwara et al., "Retention of medical doctors at the district level: a qualitative study of experiences from Tanzania," BMC Health Services Research, vol. 18, no. 1, p. 260, 2018.

[22] S. Pemba, S. B. Macfarlane, R. Mpembeni, A. J. Goodell, and E. E. Kaaya, "Tracking university graduates in the workforce: information to improve education and health systems in Tanzania," Journal of Public Health Policy, vol. 33, no. 1, pp. S202-S215, 2012.

[23] N. Sirili, A. Kiwara, F. Gasto, I. Goicolea, and A. K. Hurtig, "Training and deployment of medical doctors in Tanzania post-1990s health sector reforms: assessing the achievements," Human Resources for Health, vol. 15, no. 1, p. 27, 2017.

[24] Y. M. Dambisya, "A review of non-financial incentives for health worker retention in east and southern Africa," vol. 44, pp. 49-50, Health systems research group, Department of Pharmacy, school of health sciences, University of Limpopo, South Africa, 2007.

[25] URT, "Ministry of health and social welfare," Staffing Levels for Ministry of Health and Social Welfare Departments, Health Service Facilities, Health Training Institutions and Agencies 2014-2018, United Republic of Tanzania, 2013.

[26] URT, "Ministry of health and social welfare," National Health Policy [Draft], United Republic of Tanzania, 2003.

[27] S. Abimbola, T. Olanipekun, U. Igbokwe et al., "How decentralisation influences the retention of primary health care workers in rural Nigeria," Global Health Action, vol. 8, no. 1, p. 26616, 2015.

[28] C. Dolea, L. Stormont, and J. M. Braichet, "Evaluated strategies to increase attraction and retention of health workers in remote and rural areas," Bulletin of the World Health Organization, vol. 88, no. 5, pp. 379-85, 2010.

[29] G. M. Mbaruku, E. Larson, A. Kimweri, and M. E. Kruk, "What elements of the work environment are most responsible for health worker dissatisfaction in rural primary care clinics in Tanzania?" Human Resources for Health, vol. 12, no. 1, p. 38, 2014.

[30] URT, “Ministry of health and social welfare," Human Resource for Health Strategic Plan 2014-2019, Dar es Salaam, United Republic of Tanzania, 2014.

[31] N. Awofeso, "Improving health workforce recruitment and retention in rural and remote regions of Nigeria," Rural Remote Health, vol. 10, no. 1, p. 1319, 2010.

[32] "Tanzania Demographic and Health Survey and Malaria Indicator Survey (TDHS-MIS) 2015-16," MoHCDGEC, MoH, NBS, OCGS, and ICF, Dar es Salaam, Tanzania, and Rockville, Maryland, USA, 2016, Ministry of Health, Community Development, Gender, Elderly and Children (MoHCDGEC) [Tanzania Mainland], Ministry of Health $(\mathrm{MoH})$ [Zanzibar], National Bureau of Statistics (NBS), Office of the Chief Government Statistician (OCGS), and ICF.

[33] D. A. Mkoka, G. R. Mahiti, A. Kiwara, M. Mwangu, I. Goicolea, and A. K. Hurtig, "'Once the government employs you, it forgets you": health workers' and managers' perspectives on factors influencing working conditions for provision of maternal health care services in a rural district of Tanzania," Human Resources for Health, vol. 13, no. 1, p. 77, 2015.

[34] SPHSS-MUHAS., "Analysis of the constraints in human resource availability (training, recruitment, deployment and retention) especially in hard to reach areas," School of Public Health and Social Sciences- Muhimbili University of Health and Allied Sciences 2009, Dar es Salaampp. 1-83, 2009.

[35] L. Chen, T. Evans, S. Anand et al., "Human resources for health: overcoming the crisis," The Lancet, vol. 364, no. 9449, pp. 1984-1990, 2004. 


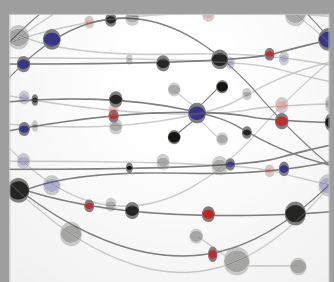

The Scientific World Journal
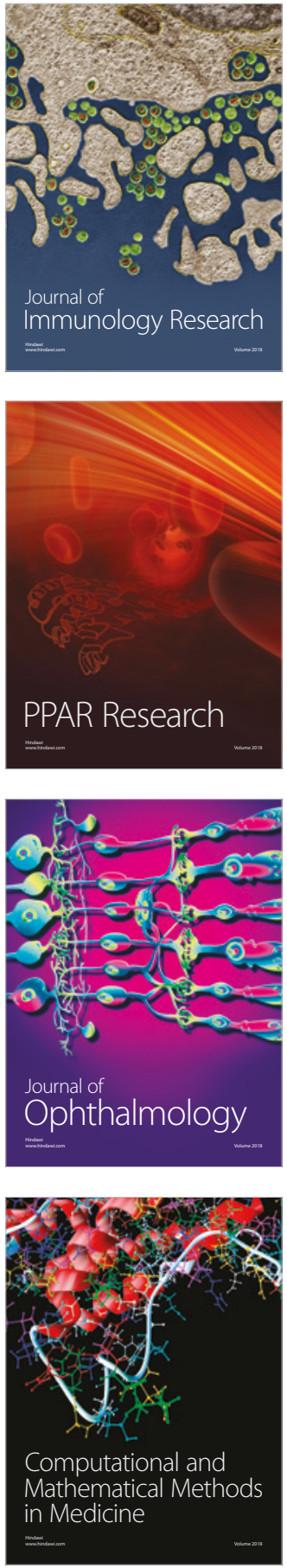

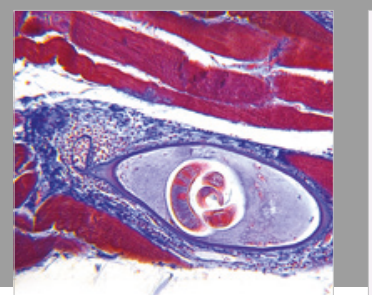

Gastroenterology Research and Practice

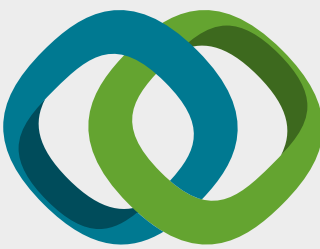

\section{Hindawi}

Submit your manuscripts at

www.hindawi.com
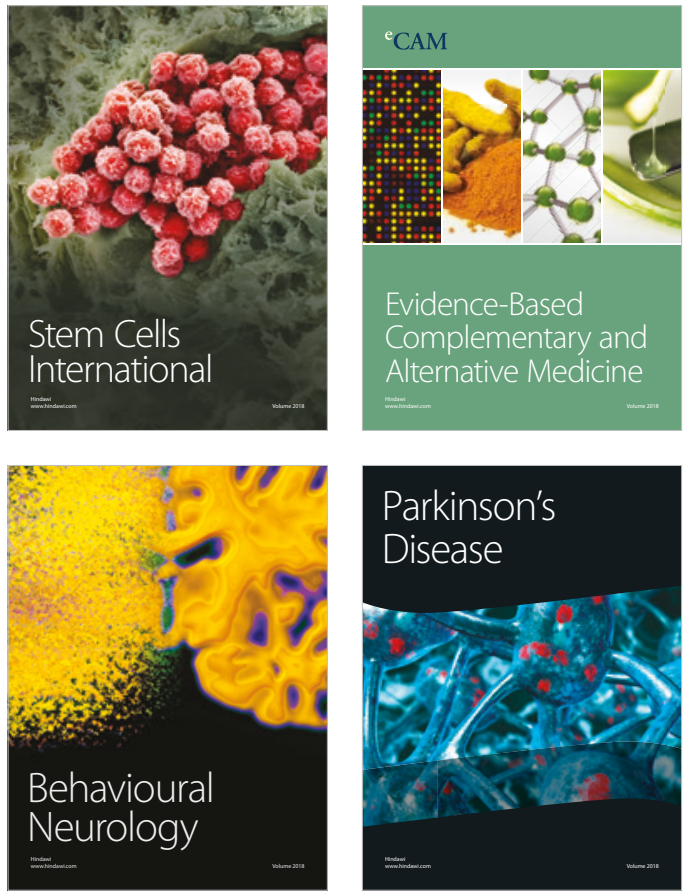

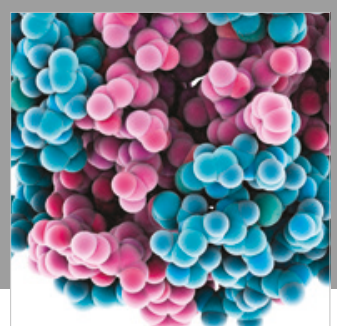

ournal of

Diabetes Research

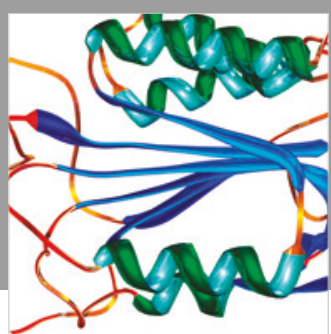

Disease Markers
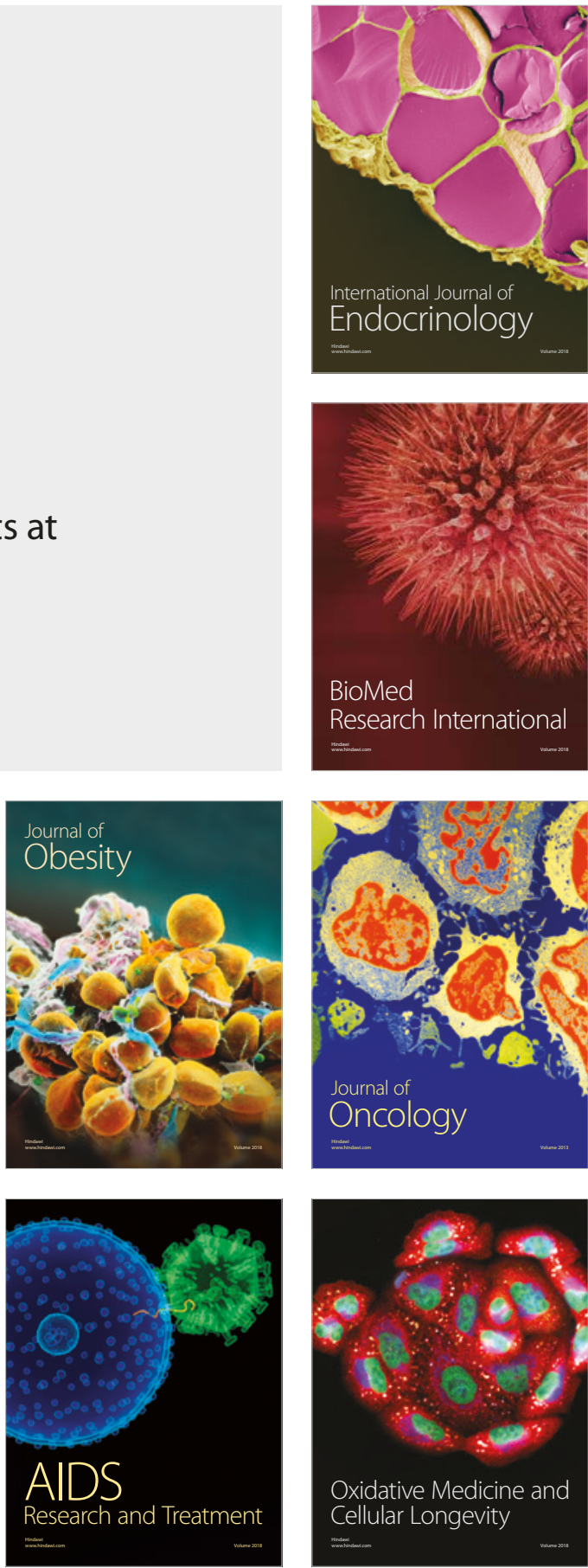